Provided for non-commercial research and education use. Not for reproduction, distribution or commercial use.

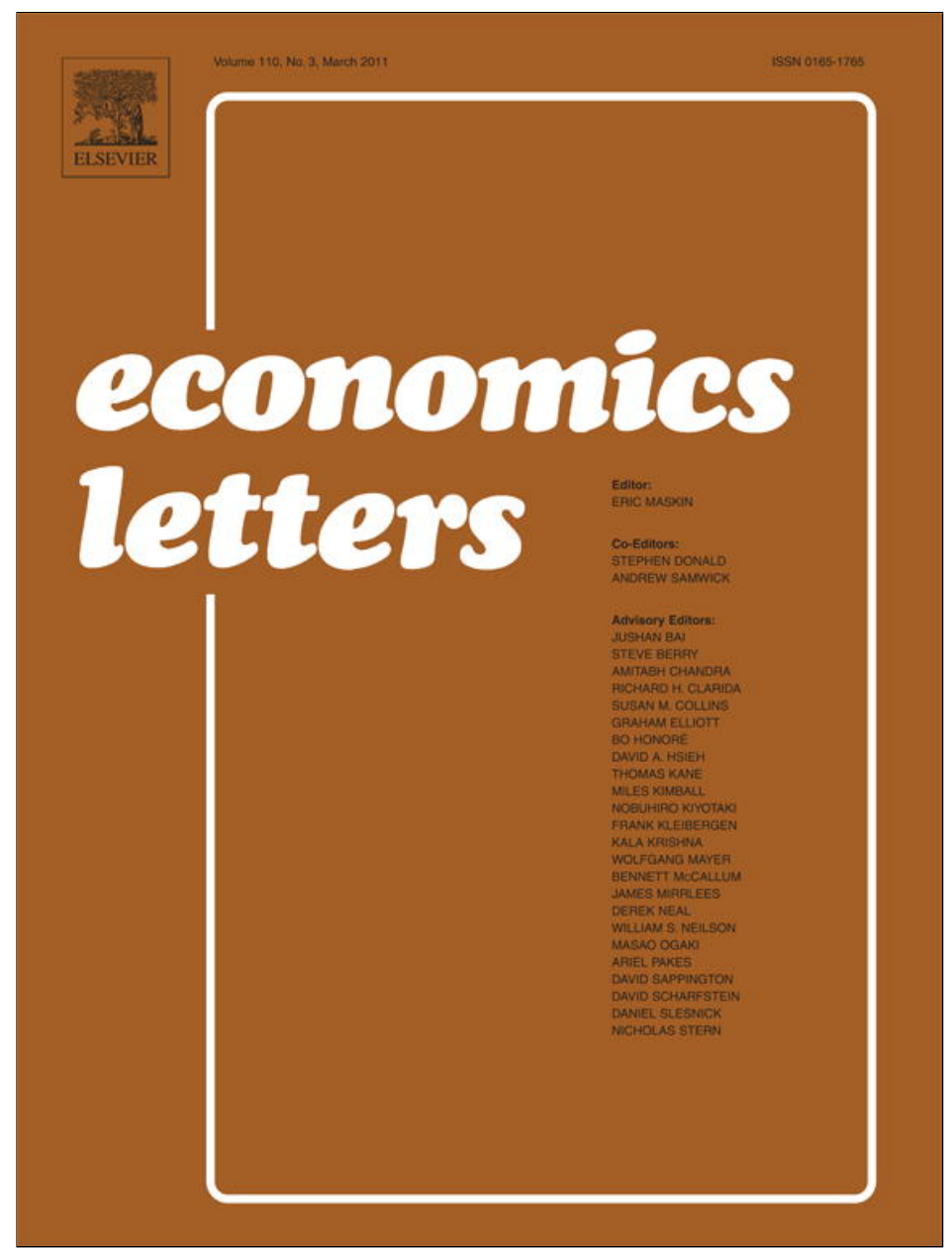

This article appeared in a journal published by Elsevier. The attached copy is furnished to the author for internal non-commercial research and education use, including for instruction at the authors institution and sharing with colleagues.

Other uses, including reproduction and distribution, or selling or licensing copies, or posting to personal, institutional or third party websites are prohibited.

In most cases authors are permitted to post their version of the article (e.g. in Word or Tex form) to their personal website or institutional repository. Authors requiring further information regarding Elsevier's archiving and manuscript policies are encouraged to visit:

http://www.elsevier.com/copyright 


\title{
Kinked norms of behaviour and cooperation
}

\author{
Sergio Currarini ${ }^{\text {a }}$, Marco Marini ${ }^{\mathrm{b}, *}$ \\ a Università degli Studi di Venezia "Cà Foscari”, Italy \\ b Università degli Studi di Urbino "Carlo Bo" E CREI, Università di Roma III, Italy
}

\section{A R T I C L E I N F O}

\section{Article history:}

Received 26 July 2010

Received in revised form 11 November 2010

Accepted 23 November 2010

Available online 2 December 2010

\section{JEL classification:}

C70

D21

D43

L13

Keywords:

Kinked demand

Symmetric games

Social norms of behaviour

\begin{abstract}
A B S T R A C T
This paper revisits a particular norm of behaviour underlying the well known model of kinked demand. We show that under some standard regularity conditions this norm of behaviour sustains the efficient outcome in all symmetric games.
\end{abstract}

(C) 2010 Elsevier B.V. All rights reserved.

\section{Introduction}

This paper focusses on the postulated behaviour of firms competing in imperfect competitive markets, first theorized in the late 30s by a number of well known economists (Robinson (1933), Sweezy (1939)), and best known as the "kinked demand model". This basically predicts an asymmetric behaviour of firms in response to a price change, each expecting its rivals to be more reactive in matching its price cuts than its price increases. This prediction has been empirically tested by Hall and Hitch (1939) and later by Bhaskar et al. (1991), extensively criticized as not grounded in rational behaviour by Stigler (1947), Domberger (1979), Reid (1981) and more recently analyzed in a dynamic settings by Marschak and Selten (1978), Maskin and Tirole (1988) and Bhaskar (1988).

In this paper we add to this debate by showing that this behavioural rule possesses strong stability properties and, therefore, may sustain firms' collusion. In particular, in a symmetric and monotone market, we prove that, if every firm adopts and expects a simple kinked demand social norm of behaviour (KSN), the symmetric collusive outcome (i.e. monopoly pricing) constitutes an

* Corresponding author. Via Saffi, 42, 60129, Urbino (PU), Italy. Tel.: +390722 305557; fax: +39 0722305550.

E-mail address: marco.marini@uniurb.it (M. Marini). equilibrium. We show that this result is rather robust and can be extended to all $n$-person symmetric strategic form games: a KSN always makes the symmetric efficient strategy profile (the one maximizing the sum of all players' utility) stable. Moreover, we show that under some additional standard assumptions on players' payoff functions, a slightly stronger norm of behaviour (implicitly implying a norm of reciprocity) makes the efficient outcome the only stable outcome of the game.

The paper is organized as follows. The next section introduces a game-theoretic setting. Section 3 concludes.

\section{A general setting}

We first introduce a class of games in which players are endowed with the same strategy space and perceive symmetrically all strategy profiles of the game. Moreover, players' payoffs possess a monotonicity property with respect to their opponents' choices. Although very specific, this setting still covers many well known economic applications (as Cournot and Bertrand oligopoly, public goods games and many others). We denote a monotone symmetric $n$-player game in strategic form as a triple $G=\left(N,\left(X_{i}, u_{i}\right)_{i \in N}\right)$, in which $N=\{1, \ldots, i, \ldots, n\}$ is the finite set of players, $X_{i}$ is player $i$ 's strategy set and $u_{i}: X_{N} \rightarrow R_{+}$is player $i$ 's payoff function, where $X_{N}=X_{1} \times \ldots \times X_{n}$ denotes the Cartesian product of players' strategy sets. We assume that each strategy set is partially ordered by the relation $\geq$. We assume the following. 
P1. (Symmetry) $X_{i}=X$ for each $i \in N$. Moreover, for every $i \in N, x \in X_{N}$ and any permutation of players' indexes $\pi(N): N \rightarrow N$

$u_{i}\left(x_{1}, x_{2}, . ., x_{n}\right)=u_{\pi(i)}\left(x_{\pi(1)}, x_{\pi(2)}, . ., x_{\pi(n)}\right)$.

P2. (Monotone Spillovers) For every $i, j \in N$ with $j \neq i$, we have either:

$u_{i}\left(x_{-j}, x_{j}^{\prime}\right) \geq u_{i}\left(x_{-j}, x_{j}\right)$ for every $x$ and $x_{j}^{\prime} \succeq x_{j}$

or

$u_{i}\left(x_{-j}, x_{j}^{\prime}\right) \leq u_{i}\left(x_{-j}, x_{j}\right)$ for every $x$ and $x_{j}^{\prime} \succeq x_{j}$,

where $x_{-j}=\left(x_{1}, . ., x_{j-1}, x_{j+1}, . ., x_{n}\right)$.

We will talk of positive spillovers (PS) when Eq. (2.2) holds and of negative spillovers (NS) when Eq. (2.3) holds. A strategy profile $x$ is symmetric if it prescribes the same strategy to all players. A Pareto Optimum (PO) for $G$ is a strategy profile $x^{0}$ such that there exists no alternative profile which is preferred by all players and is strictly preferred by at least one player. A Pareto Efficient (PE) profile $x^{e}$ maximizes the sum of payoffs of all players in $N$.

We now introduce the notion of a generic social norm of behaviour. ${ }^{1}$

Definition 1. (Social norm of behaviour). We say that the social norm of behaviour $\sigma: X \mapsto X^{n-1}$ is active in $G$ if every player $i \in N$ deviating from a given profile of strategies $x \in X_{N}$ by means of the alternative strategy $x_{i}^{\prime} \in X_{i}$ such that $x_{i}^{\prime} \neq x_{i}$, expects the response $\sigma_{N \backslash i}\left(x_{i}^{\prime}\right)$ from all players $j \in N \backslash\{i\}$.

Finally, let us introduce a general definition of stability of a strategy profile in our game $G$, under any arbitrary social norm of behaviour.

Definition 2. A strategy profile $x \in X_{N}$ is stable under the social norm $\sigma$ if there exists no $i \in N$ and $x_{i}^{\prime} \in X_{i}$ such that

$u_{i}\left(x_{i}^{\prime}, \sigma_{N \backslash\{i\}}\left(x_{i}^{\prime}\right)\right)>u_{i}(x) \forall i \in N$.

We are interested in the Kinked Social Norm (KSN) of behaviour. The original idea of the kinked demand model (Robinson, 1933; Sweezy, 1939) was based on the assumption that firms competing in a common market would react to changes in rivals' prices in an asymmetric manner. Specifically, when a firm raises its price it expects the other firms to raise their price comparatively less (under-reaction); when a firm lowers its price, conversely, it expects the others to reduce even more their price (over-reaction). If firms set quantities instead of prices the above norm of behaviour would require that firms expect their rival to over-react when increasing their quantity and under-react when decreasing their quantity. In general, this social norm can be defined in abstract terms in the way that follows.

Definition 3. (Kinked Social Norm) A Kinked Social Norm of behaviour (KSN) $\mathbf{k}$ is defined as follows: for each $i \in N$, and $x_{i}^{\prime}$ :

$\mathbf{k}_{N \backslash\{i\}}\left(x_{i}^{\prime}\right)=\left\{x_{-i} \in X^{n-1} \mid x_{j} \preceq x_{i}^{\prime} \forall j \in N \backslash\{i\}\right\}$

under positive spillovers(PS) and

$\mathrm{k}_{N \backslash\{i\}}\left(x_{i}^{\prime}\right)=\left\{x_{-i} \in X^{n-1} \mid x_{j} \succeq x_{i}^{\prime} \forall j \in N \backslash\{i\}\right\}$.

under negative spillovers(NS).

\footnotetext{
${ }^{1}$ See, for instance, Bicchieri, 1990.
}

Note that, according to the definition above, the KSN imposes to all agents in $N \backslash\{i\}$ to play a strategy lower (greater) or equal than the strategy played by the deviating player $i$ under positive (negative) spillovers. Behind the KSN of behaviour there is no presumption of rational behaviour and players' reactions may not correspond to their best reply mappings (see below for a brief digression on this point).

We are now ready to present the main result of the paper.

Proposition 1. Let conditions P1-P2 hold on G. Then, under the Kinked Social Norm of behaviour (KSN), all symmetric Pareto efficient strategy profiles of $G$ are stable.

Proof. We know by Definition 1 that KSN implies $x_{j} \preceq x_{i}^{\prime}$ for all $x_{j} \in \mathbf{k}_{N \backslash\{i\}}\left(x_{i}^{\prime}\right)$ under positive spillovers (PS) and $x_{j} \succeq x_{i}^{\prime}$ for all $x_{j} \in k_{N \backslash\{i\}}$ $\left(x_{i}^{\prime}\right)$ under negative spillovers (NS). Assume first positive spillovers (PS) on $G$ and suppose that the symmetric efficient profile (PE) $x^{e} \in X_{N}$ is not stable and there exists a $i \in N$ and a $x_{i}^{\prime} \in X_{i}$ such that

$u_{i}\left(x_{i}^{\prime}, \mathbf{k}_{N \backslash\{i\}}\left(x_{i}^{\prime}\right)\right)>u_{i}\left(x^{e}\right)$.

Using PS and the fact that $\mathbf{k}_{j}\left(x_{i}^{\prime}\right) \preceq x_{i}^{\prime}$ for every $j \in N \backslash\{i\}$, we obtain

$u_{i}\left(x_{i}^{\prime}, \ldots, x_{i}^{\prime}\right) \geq u_{i}\left(x_{i}^{\prime}, \mathbf{k}_{N \backslash\{i\}}\left(x_{i}^{\prime}\right)\right)>u_{i}\left(x^{e}\right)$

and therefore, by P1,

$\sum_{i \in N} u_{i}\left(x_{i}^{\prime}, \ldots, x_{i}^{\prime}\right)>\sum_{i \in N} u_{i}\left(x^{e}\right)$,

which contradicts the efficiency of $x^{e}$.

Assume now that under negative spillovers (NS) there exists a player $i \in N$ with a $x_{i}^{\prime} \in X_{i}$ such that

$u_{i}\left(x_{i}^{\prime}, \mathbf{k}_{N \backslash\{i\}}\left(x_{i}^{\prime}\right)\right)>u_{i}\left(x^{e}\right)$.

By NS and the fact that $\mathbf{k}_{j}\left(x_{i}^{\prime}\right) \succeq x_{i}^{\prime}$ it must be that

$u_{i}\left(x_{i}^{\prime}, \ldots, x_{i}^{\prime}\right) \geq u_{i}\left(x_{S}^{\prime}, \mathbf{k}_{N \backslash\{i\}}\left(x_{i}^{\prime}\right)\right)>u_{i}\left(x^{e}\right)$

which, again, leads to a contradiction.

Proposition 1 simply tells us that if the expected behaviour of players in the event of a deviation from an efficient strategy profile is described by the kinked social norm, then every such efficient profile, if reached, is stable. In terms of imperfect competition, the expected kinked behaviour of firms makes collusion a stable outcome.

The example below makes clear that stable inefficient (and asymmetric) outcomes cannot be ruled out without adding more structure to the above analysis.

Example 1. (2-player symmetric and positive spillovers game).

\begin{tabular}{llll}
\hline & $A$ & $B$ & $C$ \\
\hline$A$ & 4,4 & 2,3 & 1,2 \\
$B$ & 3,2 & 2,2 & 1,2 \\
$C$ & 2,1 & 2,1 & 1,1 \\
\hline
\end{tabular}

In this game we assume that players' strategy can be ordered and, e.g., $A \succ B \succ C$, therefore the game respects both P1 and P2, with positive spillovers (PS). In this game, $(A, A)$, the PE strategy profile, is obviously stable under KSN. If, say player 1 deviates playing $B$, KSN implies $k_{2}(B)=\{B, C\}$ and player 1 ends up with a lower payoff than before, since $u_{1}(A, A)>u_{1}(B, B)>u_{1}(B, C)$. By symmetry, the same happens to player 2. However, asymmetric inefficient strategy profiles as $(B, A),(A, B),(C, A)$ and $(A, C)$ are also stable under KSN, 
given that $u_{1}(B, A)>u_{1}(A, B)>u_{1}(A, C)$ and $u_{1}(C, A)>u_{1}(B, B)>u_{1}(B, C)$ and the same for player 2 .

To strengthen the result of Proposition 1 and rule out inefficient stable outcomes, we add the following assumptions on the structure of $G$.

P3. Each player's strategy set is a compact and convex subset of the set of real numbers.

P4. Each player $i$ 's payoff function $u(x)$ is continuous in $x$ and strictly quasiconcave in $x_{i}$.

Under these additional conditions, Lemma 1 in the appendix shows that there is a unique Pareto Efficient strategy profile of $G$, and it is symmetric. In order to rule out all inefficient stable outcomes, we need to refine the social norm employed in Proposition 1. Intuitively, the kinked norm imposes an upper bound on the profitability of deviations, and was therefore useful to show that efficient profiles are stable. In order to rule out the stability of inefficient profiles, we need to impose a lower bound on the profitability of deviations. We do so by imposing a "symmetric" social norm of behaviour, which essentially prescribes players to mimic the strategy adopted by a deviator.

Definition 4. (Symmetric Social Norm) The Symmetric Social Norm of behaviour (SSN) $\mathbf{s}$ is described as follows: for each $i \in N$, and $x_{i}^{\prime}$ :

$\mathbf{s}_{N \backslash\{i\}}\left(x_{i}^{\prime}\right)=\left\{x_{-i} \in X^{n-1} \mid x_{j}=x_{i}^{\prime} \forall j \in N \backslash\{i\}\right\}$.

We are now ready to prove the next proposition.

Proposition 2. Let the game G satisfy conditions P1-P4. Then, under the Symmetric Social Norm of behaviour the (symmetric) Pareto efficient profile $x^{e} \in X_{N}$ is the unique stable strategy profile.

Proof. Consider first the efficient profile $x^{e}$, which, by Lemma 1 , must be symmetric. Suppose player $i$ has a profitable deviation $x_{i}^{\prime}$. Using the Symmetric Social Norm (SSN), the expected payoff for $i$ would be $u_{i}\left(x_{i}^{\prime}, \ldots\right.$, $\left.x_{i}^{\prime}\right)$. By symmetry, the same payoff level would be obtained by all other players in $N \backslash\{i\}$. We conclude that

$\sum_{N} u_{h}\left(x_{i}^{\prime}, \ldots, x_{i}^{\prime}\right)>\sum_{N} u_{h}\left(x^{e}\right)$

which contradicts the efficiency of $x^{e}$. We next show that all inefficient profiles are not stable. The argument for inefficient symmetric profiles is trivial: thanks to the Symmetric Social Norm (SSN), it is enough for any player $i$ to switch to the efficient profile to improve upon any inefficient strategy profile. Consider then an asymmetric profile $x^{\prime}$. Let $i$ be one player such that $u_{i}\left(x^{\prime}\right)<u_{i}\left(x^{e}\right)$ (obviously, such a player must exist by efficiency of $x^{e}$ and inefficiency of $x^{\prime}$ ). By continuity of payoffs, there exists some strategy $\bar{x}_{i}$ close enough to $x_{i}^{e}$ such that

$u_{i}\left(x^{e}\right)-u_{i}\left(\bar{x}_{i}, \ldots, \bar{x}_{i}\right)<u_{i}\left(x^{e}\right)-u_{i}\left(x^{\prime}\right)$.

Since the profile $\left(\bar{x}_{i}, \ldots, \bar{x}_{i}\right)$ can be induced by player $i$ thanks to SSN, player $i$ has a profitable deviation, and the result follows.

Finally, a relevant question to raise is whether the behaviour predicted by the model of kinked demand can in general be considered rational. About this issue, it can be shown that in all symmetric supermodular games in which strategy sets are ordered, the behaviour postulated by the kinked demand model is fully compatible with players' rationality. The same cannot be said when games are submodular, i.e. when players' actions are strategic substitutes and their best responses negatively sloped.

\section{Concluding remarks}

In this paper we have shown that, for all symmetric and monotone strategic form games, the behaviour postulated by the classical model of kinked demand possesses strong stability properties. Such a result holds even stronger when players expect a fully symmetric norm of behaviour by all remaining players in the event of an individual deviation. In this case, the perfectly cooperative (collusive) outcome becomes the only stable outcome of the game, As a consequence, firms may implicitly adopt such norms of behaviour in order to implement tacit collusion and sustain perfectly collusive outcome in imperfectly competitive markets.

\section{Acknowledgments}

We wish to thank Gani Aldashev, Tom Kirchmaier, Jorn Rothe and all participants to seminars at the London School of Economics, University of Venice and University of Urbino.

\section{Appendix}

Lemma 1. Let the game G satisfy conditions P1-P4. Then, there is a unique strategy profile $x^{e}=\arg \max _{x \in X_{N}} \sum_{i \in N} u_{i}(x)$ and it is such that, $x_{1}^{e}=x_{2}^{e}=\ldots=x_{n}^{e}$.

Proof. Compactness of each $X_{i}$ implies compactness of $X_{N}$. Continuity of each player's payoff $u_{i}(x)$ on $x$ implies the continuity of the social payoff function $u_{N}=\sum_{i \in N} u_{i}(x)$. Existence of an efficient profile (PE) $x^{e} \in X_{N}$ directly follows from Weiestrass theorem. We first prove that a PE strategy profile is symmetric.

Suppose $x_{i}^{e} \neq x_{j}^{e}$ for some $i, j \in N$. By symmetry we can derive from $x^{e}$ a new vector $x^{\prime}$ by permuting the strategies of players $i$ and $j$ such that

$\sum_{i \in N} u_{i}\left(x^{\prime}\right)=\sum_{i \in N} u_{i}\left(x^{e}\right)$

and hence, by the strict quasiconcavity of all $u_{i}(x)$, for all $\lambda \in(0,1)$ we have that:

$\sum_{i \in N} u_{i}\left(\lambda x^{\prime}+(1-\lambda) x^{e}\right)>\sum_{i \in N} u_{i}\left(x^{e}\right)$.

Since, by the convexity of $X$, the strategy vector $\left(\lambda x^{\prime}+(1-\lambda) x^{e}\right) \in X_{N}$, we obtain a contradiction. Finally, by the strict quasiconcavity of both individual and social payoffs in each player's strategy, the efficient profile $x^{e}$ can be easily proved to be unique.

\section{References}

Bhaskar, V., 1988. The Kinked Demand Curve - a game theoretic approach. International Journal of Industrial Organization 6, 373-384.

Bhaskar, V., Machin, S., Reid, G., 1991. Testing a model of the Kinked Demand Curve. The Journal of Industrial Economics 39 (3), 241-254.

Bicchieri, C., 1990. Norms of cooperation. Ethics 100, 838-861.

Domberger, S., 1979. Price adjustment and market structure. Economic Journal 89, 96-108.

Hall, R.L., Hitch, C.J., 1939. Price theory and business behaviour. Oxford Economic Papers 2, 12-45.

Marschak, T., Selten, R., 1978. Restabilizing responses, inertia supergames and oligopolistic equilibria. Quarterly Journal of Economics 92, 71-93.

Maskin, E., Tirole, J., 1988. A theory of dynamic oligopoly, II: price competition, kinked demand curves and edgeworth cycles. Econometrica 56, 571-599.

Reid, G.C., 1981. The Kinked Demand Curve Analysis of Oligopoly. Edimburgh University Press, Edimburgh.

Robinson, J., 1933. Economics of Imperfect Competition. Macmillan, London.

Stigler, G., 1947. The kinky oligopoly demand curve and rigid prices. Journal of Political Economy 55, 432-447.

Sweezy, P.M., 1939. Demand under conditions of oligopoly. Journal of Political Economy 47, 568-573. 